\title{
Стадирование остеоатроза височно-нижнечелюстного сустава с помощью магнитно-резонансной томографии
}

Д. К. Али-заде ${ }^{1}$

jamila_alizade@yahoo.com

${ }^{1}$ Центральная Клиническая Больница

Ключевые слова: височно-нижнечелюстной сустав, остеоартроз, MPT.

В связи с топографо-анатомическими и морфологическими особенностями известные в артрологии классификации остеоартроза не могут быть применены для ВНЧС.

ЦЕЛЬ РАБОТЫ

Дать клинико-лучевую характеристику остеоартроза височно-нижнечелюстных суставов при различной степени выраженности заболевания по данным магнитно-резонансной томографии (МРТ).

МЕТОДИКА ИССЛЕДОВАНИЯ

Обследовано 68 пациентов с жалобами на болевые ощущения в области жевательных мышц и височно-нижнечелюстных суставов, щелчки и ограничения при открывании рта. Всем пациентам была выполнена томография на магнитно-резонансном томографе закрытого типа и индукцией магнитного поля 3,0 Тесла Siemens Magnetom Verio с использованием головной катушки.Исследование ВНЧС проводили с обеих сторон в косо корональной и косо сагиттальной плоскостях в положении закрытого и открытого до 25 мм рта с применением PD и GE импульсных последовательностейдля оценки костных и мягкотканых элементов сустава.Исследование включало в себя получение косо-сагиттальных и косо-фронтальных изображений в режиме $\mathrm{PD}$, PDFSat в положении закрытого и открытого рта. Толщина среза составляла 2,5мм с промежутком между ними в 0,2 мм. Также было проведено кинематическое исследование сустава для оценки положения диска и мыщелка в 5 различных положенияхрта. Клиническая часть обследования включала в себя сбор анамнеза и выявление жалоб.

РЕЗУЛЬТАТЫ ИССЛЕДОВАНИЯ И ИХ ОБСУЖДЕНИЯ
Таблица 1

\begin{tabular}{|c|c|}
\hline МР признаки & $\begin{array}{c}\text { Количество } \\
\text { пациентов, \% }(n=68)\end{array}$ \\
\hline $\begin{array}{c}\text { Дислокация } \\
\text { суставного диска }\end{array}$ & $68(100 \%)$ \\
\hline $\begin{array}{c}\text { Дегенеративные } \\
\text { изменения в } \\
\text { суставном диске }\end{array}$ & $30(44 \%)$ \\
\hline $\begin{array}{c}\text { Субхондральные } \\
\text { эрозии головки } \\
\text { мыщелка нижней } \\
\text { челюсти }\end{array}$ & $27(39,7 \%)$ \\
\hline $\begin{array}{c}\text { Костные разрастания } \\
\text { вдоль суставнои } \\
\text { поверхности головки } \\
\text { мыщелка нижней } \\
\text { челюсти }\end{array}$ & $19(27,9 \%)$ \\
\hline
\end{tabular}

Результаты обследования пациентов с остеоартрозом в правом и левом ВНЧС по данным МРТ (n = 127), $\mathrm{p} \leq 0,05,(\%)$

\begin{tabular}{|c|c|c|}
\hline МР признаки & $\begin{array}{c}\text { Правый } \\
\text { ВНЧС }\end{array}$ & $\begin{array}{c}\text { Левый } \\
\text { ВНЧС }\end{array}$ \\
\hline $\begin{array}{c}\text { Дислокация } \\
\text { суставного диска } \\
\text { с редукцией }\end{array}$ & $24(35,4 \%)$ & $20(29,4 \%)$ \\
\hline $\begin{array}{c}\text { Дислокация } \\
\text { суставного диска } \\
\text { без редукции }\end{array}$ & $20(29,4 \%)$ & $24(35,4 \%)$ \\
\hline $\begin{array}{c}\text { Дистрофические } \\
\text { изменения диска }\end{array}$ & $31(45,6 \%)$ & $30(44,1 \%)$ \\
\hline $\begin{array}{c}\text { Дегенеративные } \\
\text { изменения } \\
\text { сустава }\end{array}$ & $33(48,5 \%)$ & $37(54,4 \%)$ \\
\hline Наличие выпота & $44(64,7 \%)$ & $32(47,0 \%)$ \\
\hline
\end{tabular}

По данным МРТ, была обнаруженадислокация 
суставного диска (100\%), дегенерация суставного диска (44 \%), дегенеративные изменения головки мыщелка нижней челюсти $(54,4 \%)$, в том числе эрозии головки $(39,7 \%)$ и краевые костные разрастания $(27,9 \%)$, выпот в полости сустава в незначительном объеме $(64,7$ $\%)$. При этом значимых отличии ` между характером нарушении ` в правом и левом суставами не обнаружено

$(\mathrm{p} \leq 0,05)$. Поскольку при поражении одного сустава вся нагрузка перераспределяется надругой, он также подвергается структурным и морфологическим изменениям.

Была выявлена достоверная корреляционная связь между наличием дистрофических изменений суставного диска и дегенеративными изменениями суставнойголовки мыщелка нижнейчелюсти.

Наличие корреляционнойсвязи между степенью смещения и дегенеративными изменениями суставного диска подтверждает факт развития морфологических нарушении ` вслед за функциональной дискоординациеи ` в сочленении. Это необходимо учитывать для прогнозирования интенсивности развития заболевания и его исхода. Только данные МРТ диагностики позволяют это сделать объективно.Типичные изменения на МРТ ВНЧС при остеоартрозе могут быть сгруппированы соответствии с их сочетанием и степенью влияния на кинематику суставов.

I стадия - предартроз. Частичное смещение суставного диска с редукцией в нормальное положение, без дегенеративных изменении ${ }^{\circ}$ хрящевойткани суставов.

II стадия - начальный остеоартроз. Полное смещение суставного диска с редукцией. Начальные МР-признаки остеоартроза в виде уплотнения замыкательнои

пластинки суставнойголовки за счет субхондрального склероза, формирования краевых костных разрастании по передне-верхней поверхности головки мыщелка. Начальные дегенеративные изменения диска в виде незначительного изменения его конфигурации, умеренного неравномерного повышения интенсивности MP-сигнала на PD, PDFSatWI.

III стадия — умеренно выраженный остеоартроз. Полное смещение суставного диска без редукции. МР-признаки остеоартроза в виде уплотнения замыкательнои п пластинки, некрупных краевых костных разрастании ` по передне- верхней поверхности суставнойголовки с последующим еe ремоделированием, истончения и нарушения целостности суставного хряща головки мыщелка с формированием субхондральных эрозий , истончения суставного хряща и уплотнения кортикальнои “ пластинки по заднему скату суставного бугорка. Дегенеративно-дистрофические изменения суставного диска в виде изменения конфигурации

(истончение/утолщение/деформация), неоднородности структуры диска наPD, PDFSat WI.

IV стадия - деформирующий остеоартроз с наличием морфологических изменении костных и мягкотканных элементов сустава. Полное смещение суставного диска без редукции. МР-признаки деформирующего остеоартроза в виде уплощения

«грибовидной » деформации суставнои головки с неровностью контура

замыкательной пластинки за счет крупных краевых костных разрастании ` по передне верхней поверхности, наличием субхондральных эрозии ` и участков кистовидной перестрой ки костнои структуры головки мыщелка. Дегенеративнодистрофические изменения суставного диска в виде неоднородности структуры с неравномерным повышением интенсивности MP-сигнала наPD, PDFSat WI, выраженного истончения, уменьшения переднезаднего размера, с возможнои ${ }^{`}$ фрагментацией ${ }_{\text {и }}$ отсутствием его отчетливои дифференциации.В период обострения вышеперечисленные признаки I-IV стадий могут сочетаться с наличием патологического выпота в полости сустава (реактивный синовит). 

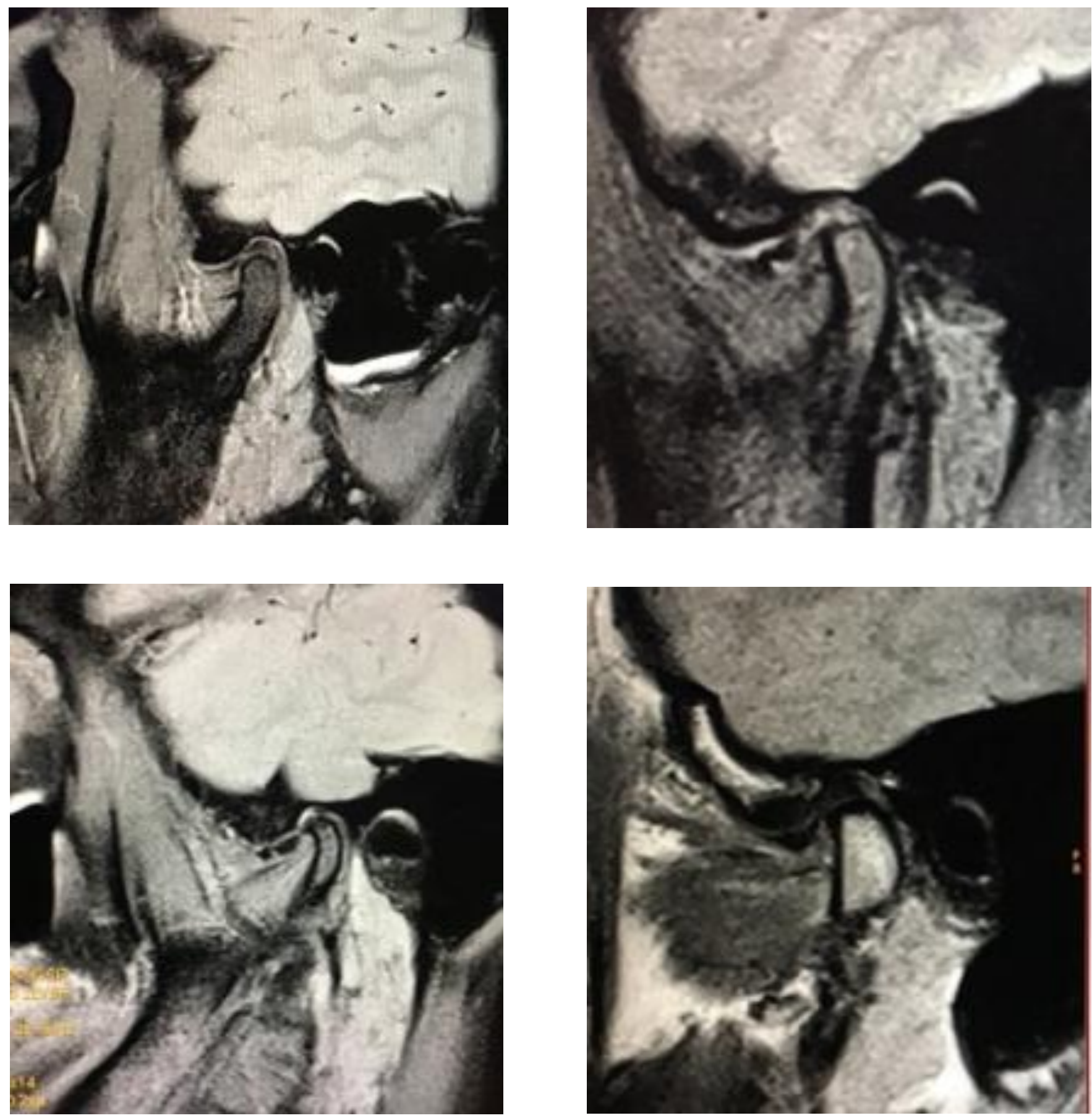


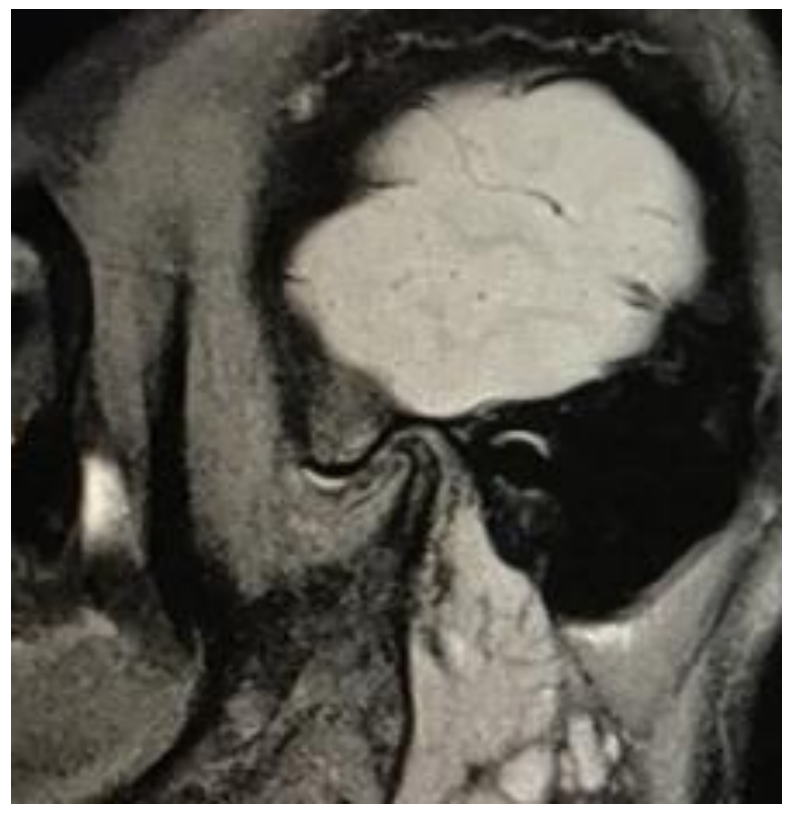

\section{ЗАКЛЮЧЕНИЕ}

По результатам лучевои ‘ диагностики пациентов с остеоартрозом ВНЧС установлено, что изменения в височнонижнечелюстных суставах могут иметь значительный диапазон - от частичнои дислокации суставного диска до выраженных деформации суставных поверхностеи ". Интенсивность нарушений имеет тенденцию увеличиваться с вовлечением в процесс все большего количества элементов сустава. Анализ результатов МРТ обследования 68 пациентов с остеоартрозом ВНЧС показал возможность выделить по принципу сочетания существенных симптомов четыре степени интенсивности нарушения.

Финансовый источник: При написании статьи не использовались финансовые ресурсы.

Конфликт интересов: Нет.

\section{СПИСОК ЛИТЕРАТУРЫ}

1. Bó WAD , Martins Junior JC , Hoyuela C , Guimarães S ， Keim FS ， et AL (2012) Efetividade da cirurgia artroscópica da ATM em pacientes com limitac, ão de abertura de boca decorrente do deslocamento anterior do disco articular sem reduc, ão: revisão de literatura . Rev Bras Cir Craniomaxilofac 15(1): 25-34.

2. 5. Tomas X., Pomes J., Berenguer J., et al. // Radigraphics. - 2006. - Vol. 26. - No 3. P. 765-781. 6. ZustinJ., AignerT. // Orthopade. - 2009. - Vol. 38. -No 6. - P. 491-500.

3. Ивасенко П. И., Савченко Р. К., Мискевич М. И., Фель- кер В. В. Заболевания височнонижнечелюстного суста- ва. - М.: Медицинская книга, 2009. - 116 с.

4. Bó WAD , Martins Junior JC , Hoyuela C, Guimarães S ， Keim FS ， et AL (2012) Efetividade da cirurgia artroscópica da ATM em pacientes com limitac, ão de abertura de boca decorrente do deslocamento anterior do disco articular sem reduc, ão: revisão de literatura . Rev Bras Cir Craniomaxilofac 15(1): 25-34.

5. Bonis RD (2007) Articulac, ão temporomandibular: estudo anato ${ }^{\wedge}$ mico e videofluoroscópico. RadiolBras 40(5): 320.)

6. Liu F, Steinkeler A (2013) Epidemiology, diagnosis, and treatment of temporomandibular disorders. Dent Clin North Am 57: 465-479

7. Ferreira LA, de Oliveira RG , Guimarães JP , Carvalho AC, De Paula MV (2013) Laser acupuncture in patients with temporomandibular dysfunction: a randomized controlled trial. Lasers Med Sci 28: 1549-1558.

8. Liu F, Steinkeler A (2013) Epidemiology, diagnosis, and treatment of temporomandibular disorders. Dent Clin North Am 57: 465-479.

9. Fujiwara M, Honda K, Hasegawa Y, Hasegawa M, Urade M (2013) Comparison of joint pain in patients diagnosed with and without articular disc displacement without reduction based on the Research Diagnostic Criteria for Temporomandibular Disorders. Oral Surg Oral Med Oral Pathol Oral Radiol Endod. 116: 9-15.

10. 16. Hunter A, Kalathingal S (2013) Diagnostic imaging for temporomandibular disorders and orofacial pain. Dent Clin North Am 57: 405418.)

11. Kawaguchi H. // Clin. Calcium. - 2008. Vol. 18. - No 9. - P. 1278-1286. 